\title{
PERIODONTAL PURVIEW IN THE MANAGEMENT OF IMPACTED ANTERIOR TEETH: A CASE SERIES
}

\author{
Sachit Anand Arora ${ }^{1}$, Shradha Kalra ${ }^{2}$, Sunny Mavi ${ }^{3}$, Abhishek Gakhar ${ }^{4}$, Shivjot Chhina ${ }^{5}$, Annapurna Ahuja ${ }^{6}$ \\ ${ }^{1}$ Professor \& Head, Department of Periodontics, I.T.S Dental College, Hospital and Research Centre, Haryana, India \\ ${ }^{2}$ PG Student, Department of Periodontics, I.T.S Dental College, Hospital and Research Centre, Haryana, India \\ ${ }^{3}$ PG Student, Department of Periodontics, I.T.S Dental College, Hospital and Research Centre, Haryana, India \\ ${ }^{4}$ PG Student, Department of Periodontics, I.T.S Dental College, Hospital and Research Centre, Haryana, India \\ ${ }^{5}$ Professor, Department of Periodontics, I.T.S Dental College, Hospital and Research Centre, Haryana, India \\ ${ }^{6}$ Reader, Department of Periodontics, I.T.S Dental College, Hospital and Research Centre, Haryana, India
}

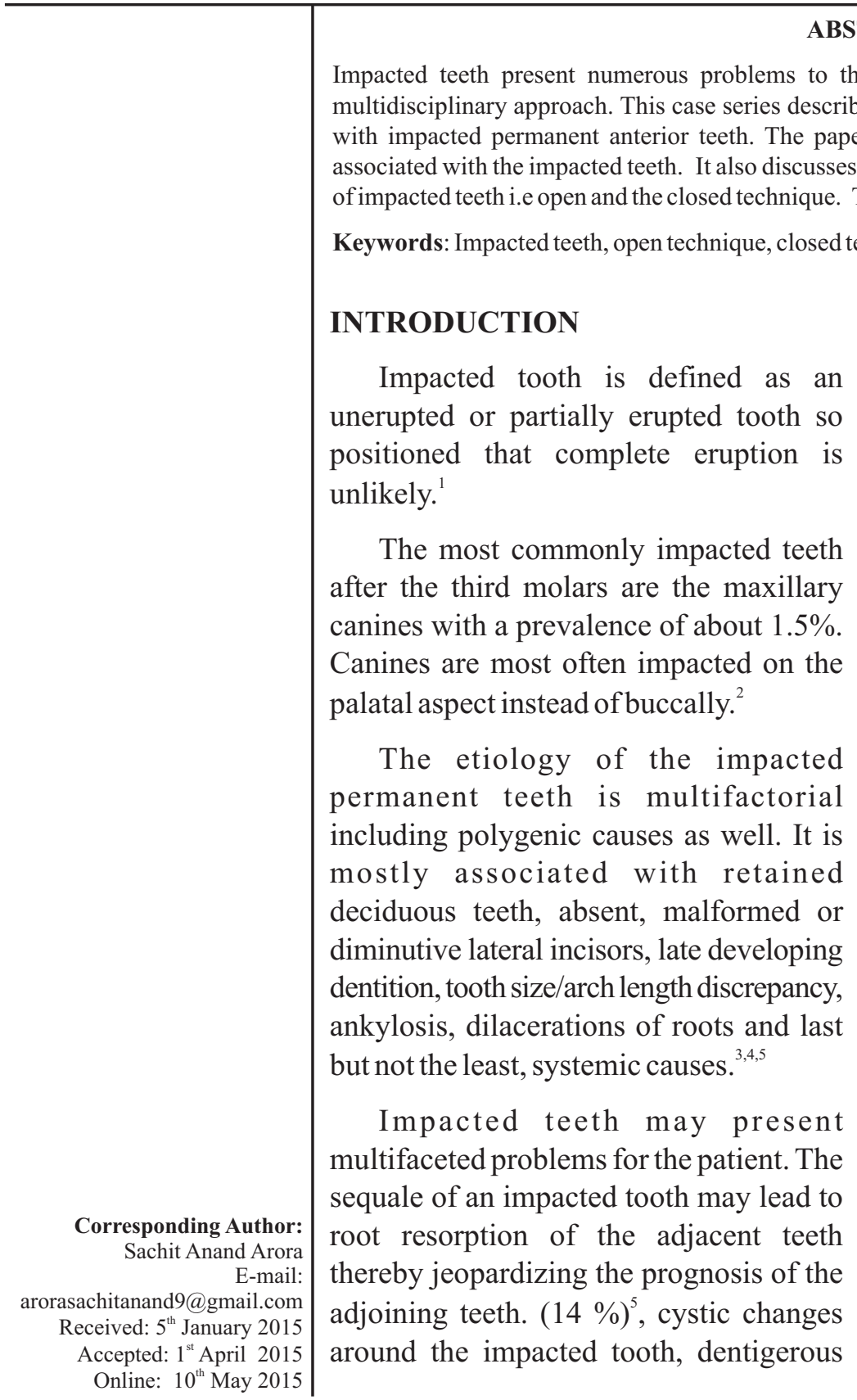

cyst for example. ${ }^{6}$ esthetic concerns, since the space in the dental arch will be unesthetic ${ }^{6}$, loss of arch length which further ahead might lead to occlusal disturbances ${ }^{7}$, mucosal perforation underneath a denture ${ }^{8}$, local infections ${ }^{9}$ and in some cases referred pain, etc. ${ }^{10}$

Orthodontist, Periodontist and the Pedodontist are the stake holders in the management of impacted teeth. The various steps of the treatment involves firstly the pedodontist giving an early diagnosis of impacted teeth. The orthodontist intervenes presurgically for creation of space and the periodontist for the surgical exposure of the tooth.

On history \& clinical examination the teeth are usually palpable in the buccal vestibule 1-2 years before their eruption time. ${ }^{11,12}$ After the age of 10-11 years absence of palpable canines or other teeth accordingly in the sulcus should direct the clinician towards radiographic assessment. The radiographic examination ${ }^{12,13}$ include anterior occlusal and periapical radiographs, two periapicals, anterior occlusal (70-75 degree) and optical projection 
tomography (OPT). The advancement in the technology gives the clinician another option of a CBCT which would locate an impacted tooth precisely. ${ }^{13}$

\section{MANAGEMENT TECHNIQUES: $:^{14}$}
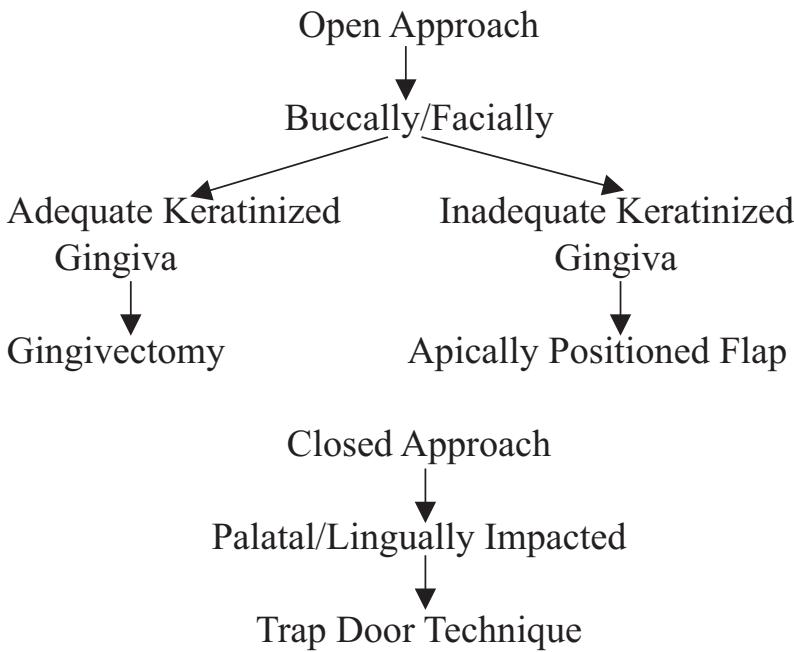

\section{CASE REPORTS:}

This case series presents the cases of three patients undergoing surgical exposure of impacted maxillary central incisor and canine to facilitate the orthodontic treatment.

\section{Case Report 1}

A female patient aged 22 years was referred from the department of Orthodontics to the department of Periodontics, I.T.S Dental College, Hospital \& Research Centre, Greater Noida for the surgical exposure of impacted maxillary right central incisor (11). The over retained primary tooth was extracted before intiating the orthodontic treatment.

On clinical examination, a bulge was palpable in the vestibule area mesial to the maxillary right lateral incisor. On radiographic examination i.e intraoral periapical view and occlusal view of the maxilla, an impacted maxillary central incisor could be noted on the right side.

After thorough clinical and radiographic examination, an apically positioned flap with ostectomy procedure was decided. The procedure was carried out by reflecting a full thickness flap which was displaced apically and sutured using 4-0 silk sutures. Suture removal was done 10 days post-operatively and an orthodontic bracket was placed on the exposed tooth. Initially a lingual button was bonded on the exposed tooth surface and ligated to archwire. Once the tooth started erupting and the $2 / 3$ rd of the crown was visible in the oral cavity, the MBT bracket was bonded at the ideal position. A light arch wire was fully ligated. On 6 months post-operative examination, the tooth had erupted completely into the oral cavity (Figures 1-6).
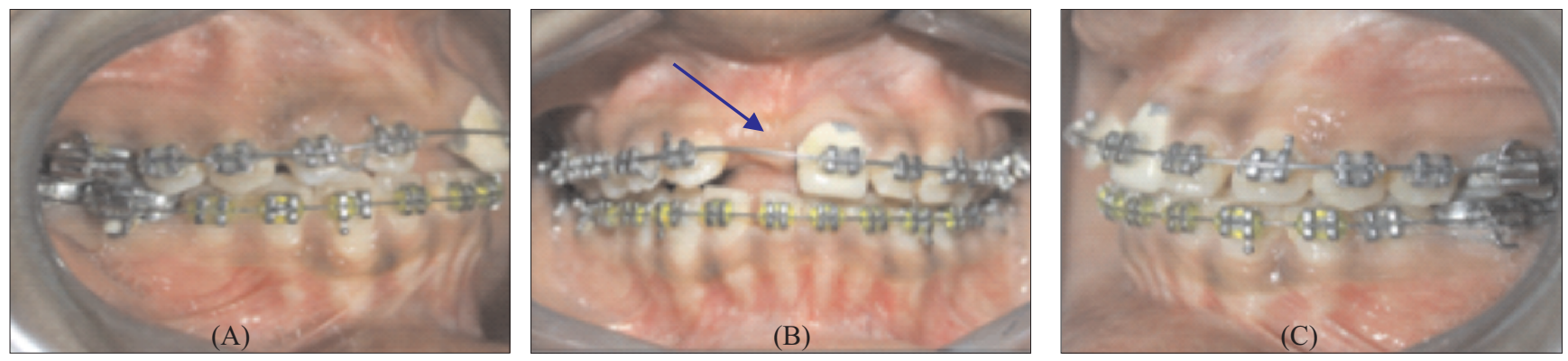

Figure $1(\mathrm{~A}, \mathrm{~B}, \mathrm{C})$ : Pre-operative view depicting the bulge of the impacted maxillary right central incisor (Case 1$)$

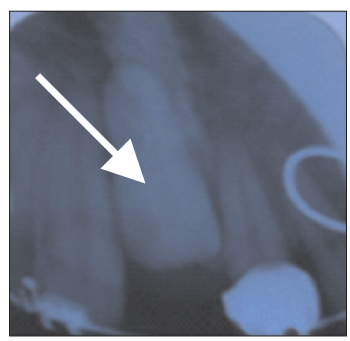

Figure 2: IOPA depicting the impacted maxillary right central incisor (Case 1)

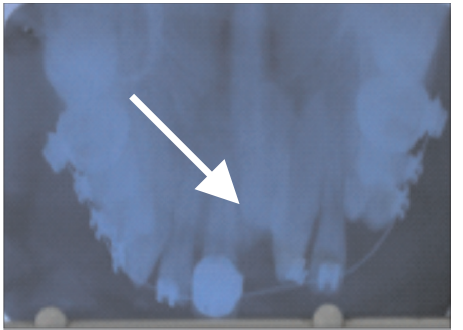

Figure 3: Occlusal view radiograph (maxillary) depicting the impacted maxillary right central incisor (Case 1) 


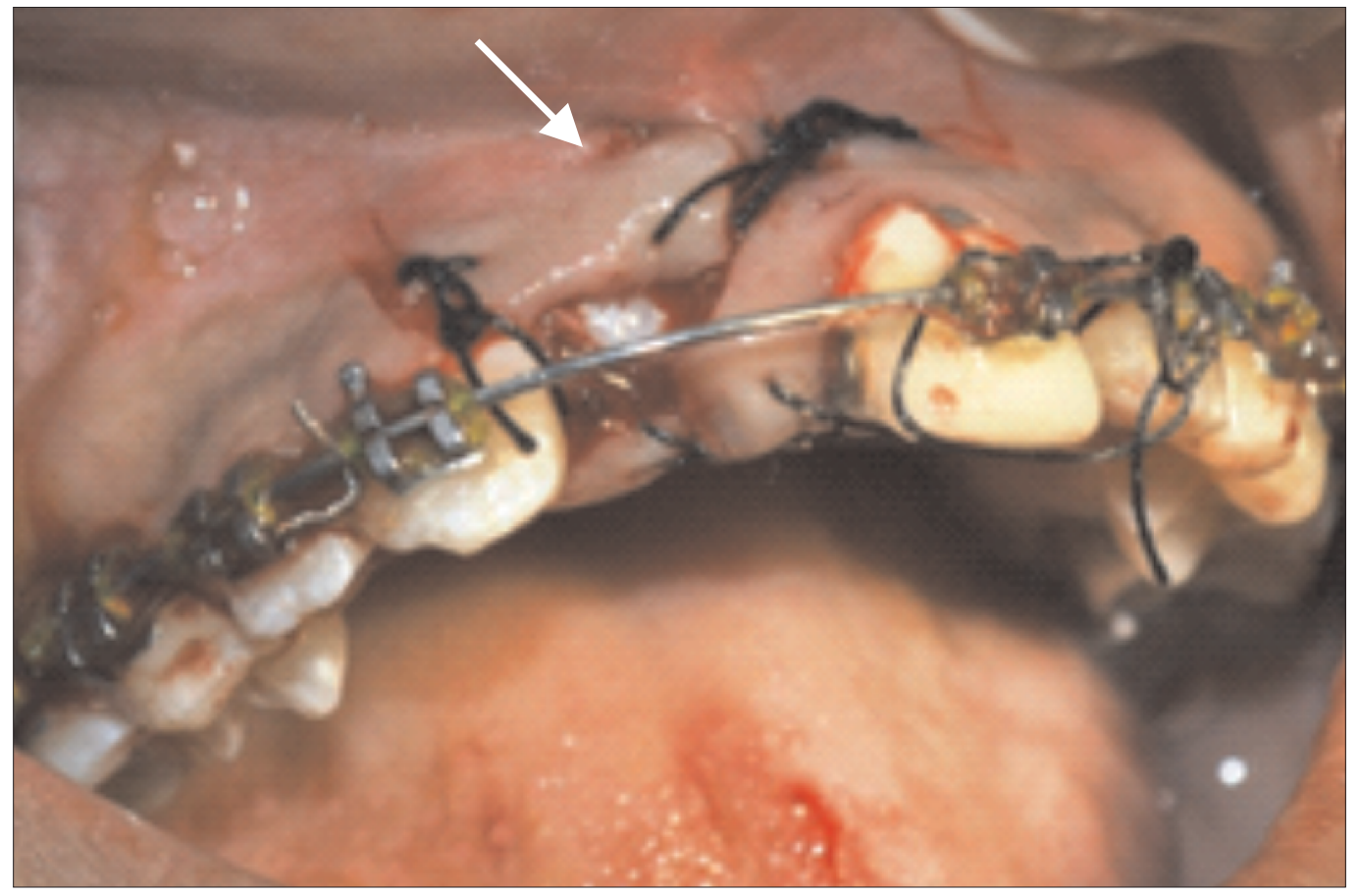

Figure 4: Immediate post-operative view of the exposed impacted tooth (Case 1)

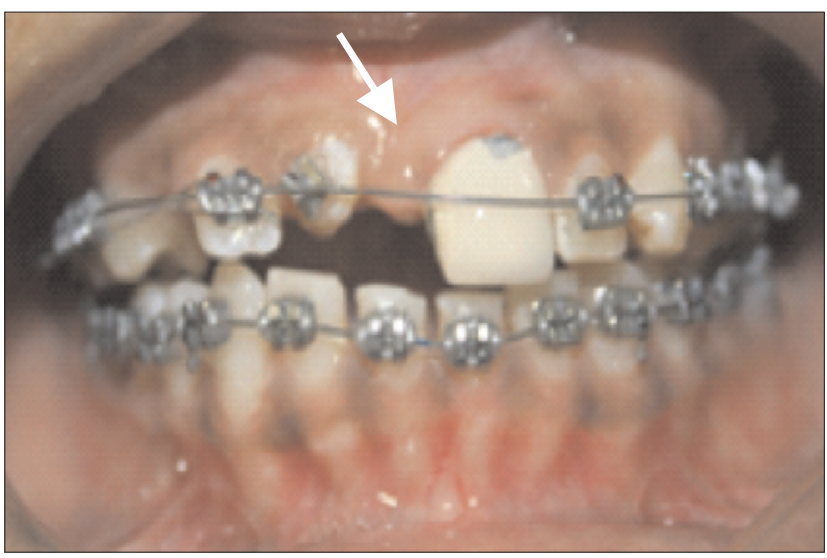

Figure 5: Three months post-operative view showing partial extrusion of maxillaryright central incisor (Case 1)

\section{Case Report 2:}

A male patient aged 24 years was referred from the department of Orthodontics to the department of Periodontics, I.T.S Dental College, Hospital \& Research Centre, Greater Noida for the surgical exposure of impacted canine (23). On clinical and radiographic examination, the maxillary left canine was found to be palatally impacted. On bone sounding, the crown of the tooth was found to

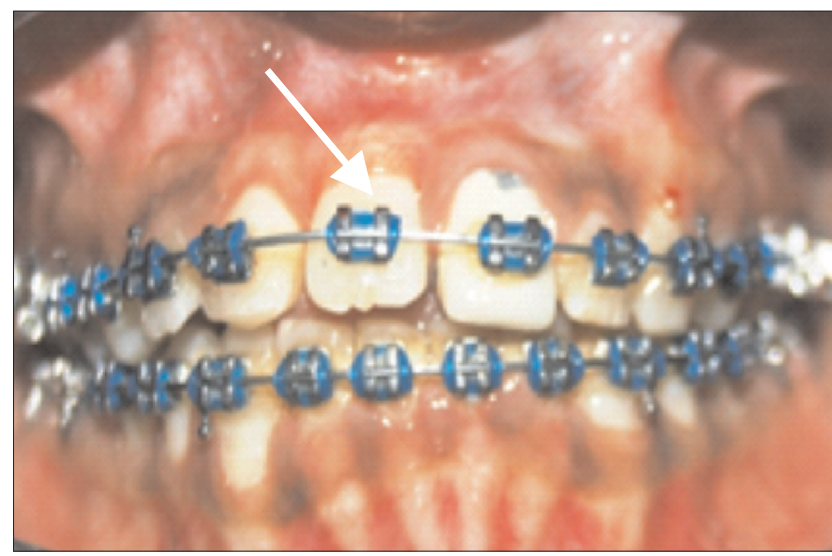

Figure 6: Six months post-operative view showing erupted maxillary right central incisor (Case 1)

be overlaid with bone plate. The treatment protocol decided was to reflect a full thickness flap along with osteoctomy for sufficient exposure of tooth surface. A soft tissue window was created using electrocautery (ART E 1 Electrosurge, BonART Co. Ltd, US) for exposure of the crown. The flap was sutured back into position. Ball attachment was placed on the exposed crown immediately after the surgery for applying the orthodontic forces (Figures 7-11). 


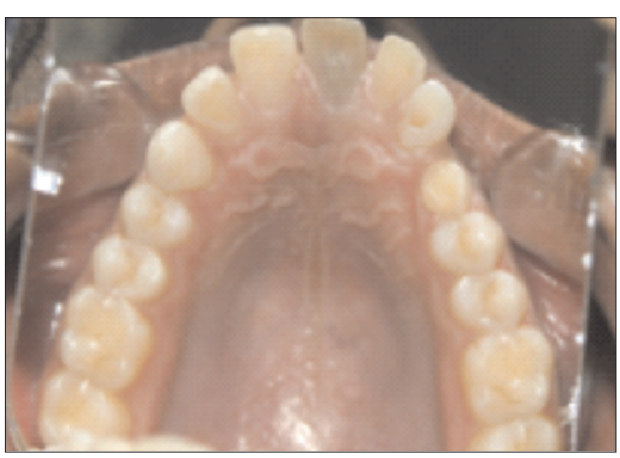

Figure 7: Pre-operative view depicting the bulge of the impacted maxillary left canine (Case 2)

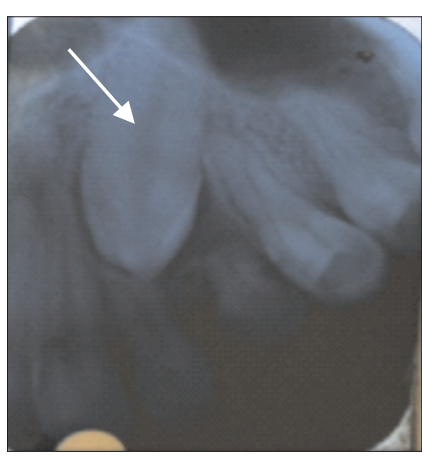

Figure 8: IOPA depicting the bulge of the impacted maxillary left canine (Case 2)

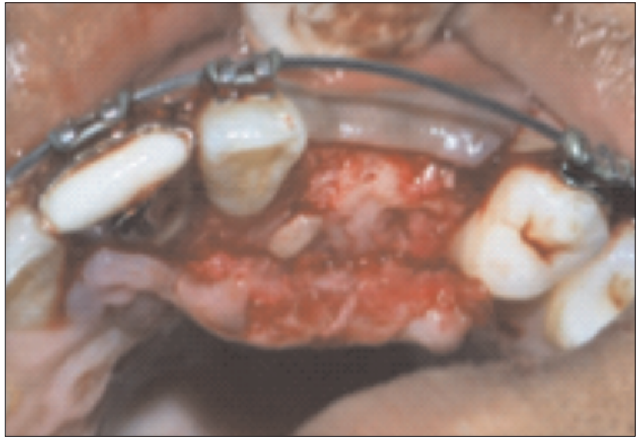

Figure 9: Mucoperiosteal flap reflected (Case 2)

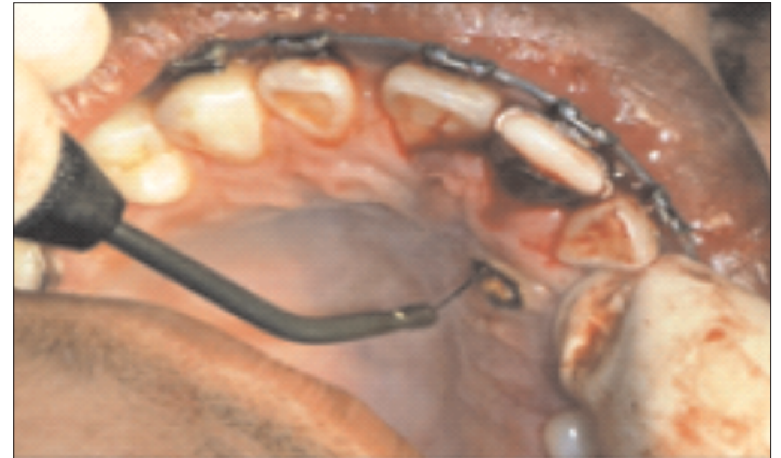

Figure 10: Soft tissue window created using Electrocautery to expose the impacted teeth (Case 2)

\section{Case Report 3:}

A female patient aged 23 years was referred from the department of Orthodontics to the department of Periodontics, I.T.S Dental College, Hospital \& Research Centre, Greater Noida for the surgical exposure of impacted maxillary and mandibular canines. On clinical examination, the bulge of the maxillary and mandibular canines were palpable on the labial aspect. On radiographic examination, the patients CBCT revealed the soft tissue impaction of all

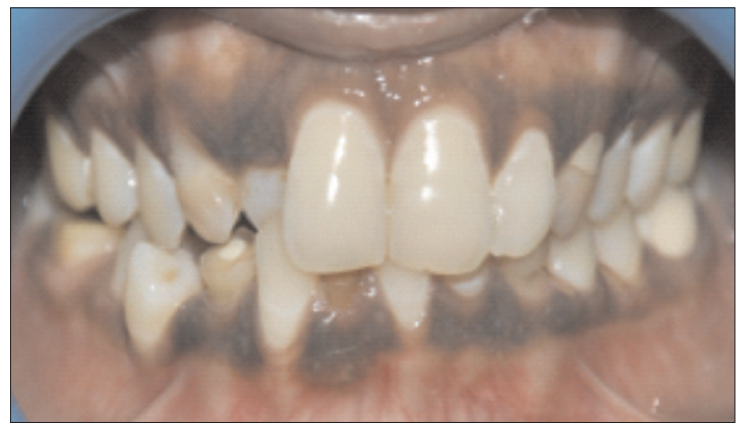

Figure12: Pre operative view depicting the bulge of the impacted maxillary and mandibular canines (Case 3 )

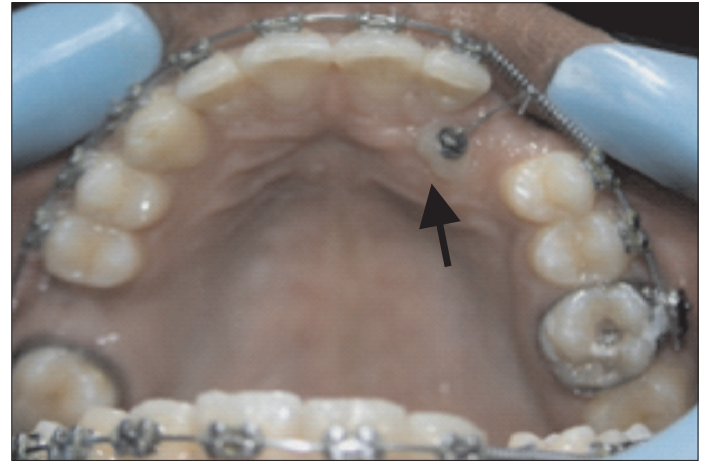

Figure 11: Three Months post-operative view showing partial extrusion of maxillary left canine (Case 2)

the four canines. Accordingly a treatment plan was formulated and it was decided to create soft tissue window using diode laser. The laser (Dental diode laser-photon plus 10 watt, ZolarTM Technology \& Mfg Co. Inc, Ontario, Canada) was set at a power setting of 1 Watt. Laser was used in pulsed, contact mode. The Orthodontic bracket was bonded immediately to the exposed tooth surface so as to prevent the soft tissue overgrowth. Active forces were applied 2 weeks postoperatively (Figures 12-15).

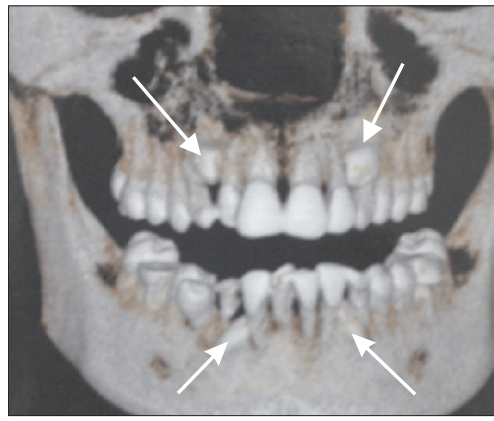

Figure 13: CBCT showing the exact position of the impacted maxillary and mandibular canines (Case 3) 


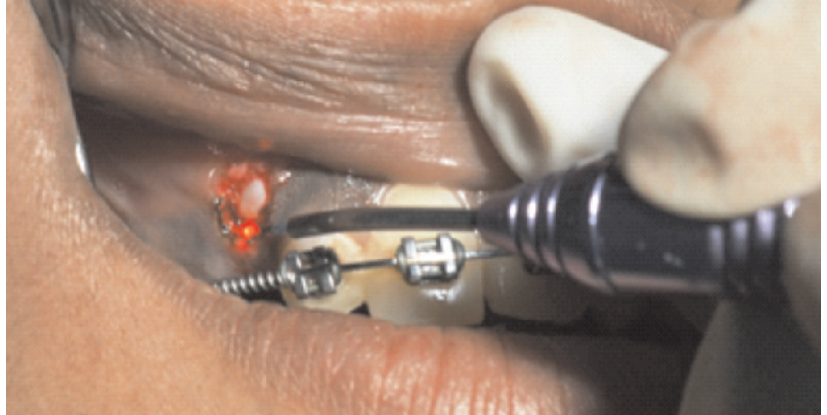

Figure 14: Soft tissue window created using Diode Laser to expose the impacted maxillary right canine (Case 3)

\section{DISCUSSION}

Exposure and management of impacted teeth is both time consuming and expensive and involves surgical exposure (uncovering) followed by fixed orthodontic therapy for 2 to 3 years to bring the impacted tooth into alignment within the dental arch. Two techniques for exposing impacted teeth which are routinely used are the closed technique and the open technique. The closed technique involves orthodontically moving the impacted tooth into its correct position beneath the mucosa and the open technique involves orthodontically moving the impacted tooth into its correct position after its exposure (no soft tissue covering).

The procedure followed for the reported cases was the open technique. The advantages of following the open technique were the better visibility of the tooth and lesser time duration to get the tooth in its position 16. In the first case at the 12 months recall visit the previously impacted maxillary right central incisor was brought in its predetermined position in the dental arch. On periodontal evaluation of the tooth and the adjacent teeth, adequate keratinized tissue was found, no tooth mobility was detected and the root had a normal anatomical form. The patient was highly satisfied with the results.

The second and third cases in the series were treated with creation of soft tissue window for the attachment of orthodontic tooth bracket and active forces were immediately started on them. The cases are being followed up for the periodontal evaluation.

Burden $1999^{15}$, reviewed both the open and the closed technique in terms of periodontal health and concluded that there was no evidence to support either

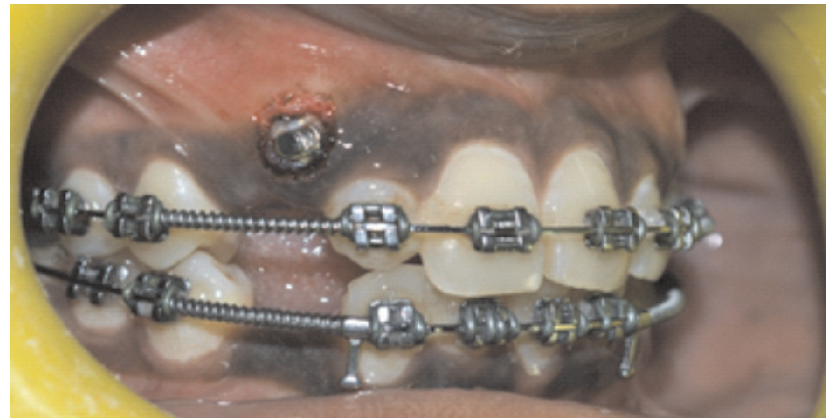

Figure 15: Bracket attached for orthodontic therapy immediately after surgery (Case 3 )

technique.

Wisth $1976^{16}$, also compared the closed and open techniques. The mean duration of treatment was 4 months or longer in the closed group which was attributed to lack of direct vision of the impacted tooth from when it was exposed and sequentially brought into the dental arch. The teeth treated with the closed technique had less periodontal damage i.e. loss of attachment and bone levels.

Schmidt $2007^{17}$, conducted a study comparing the periodontal health, root length and aesthetics in cases with unilaterally and bilaterally palatally displaced canines. Open technique was used for the exposure and the canines were allowed to erupt autonomously, later being brought into their position in the dental arch with fixed orthodontic appliances. The outcomes were compared to the contra-lateral untreated canine. Another similar study was done by Woloshyn ${ }^{18}$, where all palatally displaced canines received a closed exposure. Both studies found that the roots of the impacted canine and adjacent lateral incisor were slightly shorter than those of the contra-lateral canine and that the treated canine could be visually identified from the untreated canine in $70 \%$ to $80 \%$ of cases. Woloshyn, also found significant differences in probing depths and crestal bone height when comparing, treated with untreated canines; which was not in concordance to the Schmidt's study. It was concluded that the overall consequences to the impacted canine with this technique seems better than with a closed technique, however consequences to the lateral incisor were similar with both techniques. ${ }^{19}$

This is in contrast to findings of other authors like Becker \& coworkers $^{20}$ and Crescini \& coworkers $^{21}$ 
These authors reported excellent periodontal health following alignment of canines using a closed technique. Importantly, all these mentioned studies (including that by Schmidt), are retrospective studies and their findings therefore, score low in terms of evidence. ${ }^{19}$

\section{CONCLUSION}

This case series presented the exposure of impacted teeth using two techniques i.e open technique and the trap door technique. Also it presented the discussion of open technique versus the closed technique and the advantage of one over the other. The periodontal evaluation of the exposed impacted tooth in the first case showed satisfactory results. To conclude, currently there isn't much evidence to support one specific surgical technique in terms of factors like dental health, aesthetics, economics and patient satisfaction. Further clinical trials with more number of participants in the two treatment groups needs to be conducted. Methods of exposing impacted teeth are better left to the choice of the periodontist and orthodontist.

\section{ACKNOWLEDGEMENT}

The authors acknowledge the contributions of the I.T.S Dental College, Hospital \& Research Centre, Greater Noida for their support in this project.

\section{REFERENCES}

1. American Academy of Periodontology. Glossary of Periodontal terms, 4th edn. American Academy of Periodontology 2001, Chicago, Illinois.

2. Thilander B, Myrberg N. The prevalence of malocclusion in Swedish schoolchildren. Scandinavian J Dent Res 1973;81(1):12-21.

3. Bishara SE. Impacted maxillary canines: a review. Am J Orthod Dentofacial Orthop. 1992;101:159- 171.

4. Moyers RE: Handbook of Orthodontics, 2nd ed. Chicago; Year Book Medical Publishers Inc, 1963 pp 83-88.

5. Peck S, Peck L, Kataja M. Prevalence of tooth agenesis and peg shaped maxillary lateral incisor associated with palatally displaced canine (PDC) anomaly. Am J Ortho Dentofacial Orthopedics 1996;110(4):441-3.
6. Shafer WG, Hine MK, Levy BM. A textbook of oral pathology. 4th Edition. Philadelphia, PA: Saunders, 1983:66-9.

7. Nordenram Ä. Impacted maxillary canines - A study of surgically treated patients over 20 years of age. Swed Dent J 1987;11:153-158.

8. Shapira Y, Kuftinec MM. Early diagnosis and interception of potential maxillary canine impaction. J Am Dent Assoc. 1998;129:1450-1454.

9. Yamaoka M, Furusawa K, Yamamoto M. Influence of adjacent teeth on impacted third molars in the upper and lower jaws. Aust Dent J 1995;40:233-5.

10. Kuftinec MM, Shapira Y. The impacted maxillary canine: I. Review of concepts. J Dent Child 1995;62:317-324.

11. Ngan P, Hornbrook R, Weaver B. Early timely management of ectopically erupting maxillary canines. Semin Orthod. 2005;11:152-163.

12. Bedoya MM, Park JH. A review of the diagnosis and management of impacted maxillary canines. J Am Dent Assoc. 2009;140:1485-1493.

13. Isaacson KG, Thom AR, Horner K, Whaites E. Orthodontic Radiographs- Guidelines, 3rd edition. London: British Orthodontic Society, 2008.

14. Mason C, Papadakou P, Roberts GJ. The radiographic localization of impacted maxillary canines: A comparison of methods. Eur J Orthod 2001; 23: 25-34.

15. Burden DJ, Mullally BH, Robinson SN. Palatally ectopic canines: closed eruption versus open eruption. Am J of Orthodontics and Dentofacial Orthopedics 1999;115(6):640-4.

16. Wisth PJ, Norderval K, Booe OE. Comparison of two surgical methods in combined surgical-orthodontic correction of impacted maxillary canines. Acta Odontologica Scandinavica 1976;34(1): 53-7.

17. Schmidt AD, Kokich VG. Periodontal response to early uncovering, autonomous eruption, and orthodontic alignment of palatally impacted maxillary canines. Am J Ortho \& Dentofacial Orthopedics 2007;131(4):449-55.

18. Woloshyn H, Artun J, Kennedy DB, Joondeph DR. Pulpal and periodontal reactions to orthodontic alignment of palatally impacted canines. Angle Orthodontist 1994;64(4):257-64.

19. Parkin N, Benson PE, Thind B, Shah A. Open versus closed surgical exposure of canine teeth that are displaced in the roof of the mouth (Review). The Cochrane Library 2008; 4: 1-12.

20. Becker A, Kohavi D, Zilberman Y. Periodontal status following the alignment of palatally impacted canine teeth. Am J Ortho 1983;84(4):332-6.

21. Crescini A, Nieri M, Buti J, Baccetti T, Mauro S, Prato GP. Short and long-term periodontal evaluation of impacted canines treated with a closed surgical-orthodontic approach. J Clin Periodontol 2007;34(3):232-42. 